\title{
Analysis of Polymorphisms Associated with Base Excision Repair in Patients Susceptible and Resistant to Noise-Induced Hearing Loss
}

\author{
Enmin Ding $\left(\mathbb{D},,^{1}\right.$ Jiadi Guo $\mathbb{D}^{2},{ }^{2}$ Xin Ge $\mathbb{D}^{\mathbb{D}},,^{3}$ Rongjian Sheng $\left(\mathbb{D},,^{3}\right.$ Jian Chen $\left(\mathbb{D},,^{3}\right.$ \\ Hengdong Zhang, ${ }^{1}$ and Baoli Zhu ${ }^{2}{ }^{2}$ \\ ${ }^{1}$ Jiangsu Provincial Center for Disease Prevention and Control, Institute of Occupational Disease Prevention, Nanjing, \\ Jiangsu Province, China \\ ${ }^{2}$ Center for Global Health, School of Public Health, Nanjing Medical University, Nanjing, Jiangsu Province, China \\ ${ }^{3}$ Yizheng Hospital, Drum Tower Hospital Group of Nanjing, Yizheng, Jiangsu Province, China
}

Correspondence should be addressed to Baoli Zhu; zhubljscdc@126.com

Received 8 April 2019; Revised 30 August 2019; Accepted 10 September 2019; Published 14 November 2019

Academic Editor: Marco E. M. Peluso

Copyright (c) 2019 Enmin Ding et al. This is an open access article distributed under the Creative Commons Attribution License, which permits unrestricted use, distribution, and reproduction in any medium, provided the original work is properly cited.

\begin{abstract}
Objective. Noise-induced hearing loss (NIHL) is one of the most common occupational health risks in both developed and industrialized countries. It occurs as a result of interactions between genetic and environmental factors. Nevertheless, inherited genetic factors contributing to NIHL are not well understood. Therefore, we aim to investigate whether genetic mutations in three important base excision repair genes (OGG1, APEX1, and XRCC1) may influence susceptibility to NIHL. Methods. Three SNPs in OGG1, APEX1, and XRCC1 were genotyped from 1170 noise-exposed workers and were classified into 117 most susceptible and 117 most resistant individuals. Results. Results showed that the rs1799782 TT genotype located in the XRCC1 coding region and rs1130409 GG/GT in the APEX1 coding region were associated with increased risk for NIHL in a Chinese population. Compared to the rs1799782 $\mathrm{C}$ allele frequency, the $\mathrm{T}$ allele frequency was increased in the sensitive group (adjusted $\mathrm{OR}=1.51,95 \% \mathrm{CI}=1.01$ to $2.26, P=0.043)$. The rs1130409 $\mathrm{G}$ allele frequency was also increased in the sensitive group compared to the resistant group (adjusted $\mathrm{OR}=1.59,95 \% \mathrm{CI}=1.10$ to $2.31, P=0.015$ ). Moreover, rs1130409 and drinking had a statistically significant interaction $(P=0.0002)$, while rs1799782, rs1130409, and smoking also had a statistically significant interaction $(P<0.0001)$. Conclusions. XRCC1 rs1799782 and APEX1 rs1130409 may have potential as biomarkers for the screening of susceptibility to NIHL in workers exposed severe noise.
\end{abstract}

\section{Introduction}

Noise-induced hearing loss (NIHL) has been the second most common form of severe sensorineural hearing impairment, besides age-related hearing loss (ARHL). It is one of the leading occupational diseases both in developed and industrialized countries [1].

NIHL is a complex disease, caused by interactions between genetic and environmental factors, with large differences in hearing loss occurrence after similar noise exposure $[2,3]$. This interindividual variability has been considered to be due to interactions between genetic and environmental factors, as well as living habits. It is believed that besides noise, ototoxic substances, heat, vibrations, and individual factors such as age, smoking, and blood pressure have an effect on the development of NIHL [4]. Numerous variations in susceptibility to NIHL have been reported. Single nucleotide polymorphisms (SNPs) are known as the most common form of genetic variation in the mammalian genome, with about 15 million SNPs found among all humans. So far, SNPs in genes such as FOXO3, DNMT, HSP70, CAT, Notch, and KCNQ4 have been identified in many association studies regarding NIHL involving human subjects [5-10].

DNA repair is the most important defense mechanism against DNA lesions, which are caused by environmental factors and normal metabolic activity in humans [11]. DNA 
damage is identified and processed by a variety of distinct pathways collectively called the "DNA damage response (DDR)" pathways [12]. DDR includes mechanisms such as direct repair (DR), mismatch repair (MMR), double-strand break repair (DSBR), nucleotide and base excision repair (NER and BER), and DNA interstrand crosslink repair $[13,14]$. BER, a key mechanism of the DNA repair pathway, mainly plays a role in repairing damage to single bases in DNA molecules. BER is the main guard against DNA damage as a result of both normal and abnormal cellular metabolism, including methylation, deamination, hydroxylation, reactive oxygen radicals, and physical and chemical factors (such as $\mathrm{X}$-rays and alkylating agents) [15]. Moreover, the BER pathway is the primary mechanism that defends against oxidative stress-induced DNA damage in cells. BER is known to act on small DNA lesions or modified bases to repair damage by removing and replacing damaged base pairs. Enzymes involved in BER include human 8-oxoG DNA glycosylase1 (hOGG1), apurinic/apyrimidinic endonuclease 1 (APE1 or $A P E X 1)$, and the $\mathrm{X}$-ray repair cross-complementing group 1 (XRCC1). Variations that occur in BER-related gene regions can lead to abnormality of repair functions, increasing the probability of developing diseases [16].

Numerous studies have reported on the association of genetic factors, including DNA synthesis-related genes, DNA repair pathways, cell cycle control, and apoptosis, with NIHL individual susceptibility of workers exposed to industrial noise. Shen et al. showed that the APEX1 rs1130409 and hOGG1 rs1052133 polymorphisms contribute to the susceptibility of NIHL in Chinese populations [17, 18]. However, this conclusion is slightly controversial, as the study included an insufficient number of samples compared to the study conducted by Konings et al. [8], which included 1261 Swedish and 4500 Polish, noise-exposed labourers. Moreover, the association between polymorphisms of the XRCC1 gene and NIHL susceptibility was not reported before.

In this study, we aim to investigate whether BER genes are associated with susceptibility to NIHL in 117 sensitive and 117 resistant individuals selected from a cohort of 1170 noiseexposed workers. By using the Single Nucleotide Polymorphism Database (dbSNP data), three putative SNPs in $h O G G 1$ (rs2072668), APEX1 (rs1130409), and XRCC1 (rs1799782) were selected and the genetic interactions of these three polymorphisms and their relation to NIHL risk among the Northern Han Chinese population were evaluated.

\section{Patients and Methods}

2.1. Patients. A total of 1170 noise-exposed workers from a single factory located in northern China were enrolled in the current study in December 2017. Informed consent was obtained from all individual participants, and research was approved by the ethical committee of the Jiangsu Provincial Center for Disease Prevention and Control. Patient data, including general information, lifestyle, past medical history, and exposure to chemical/physical factors, was gathered. To exclude confounding factors other than genetic susceptibility as much as possible, out of the 1170 workers, we selected the $10 \%$ which were most susceptible and most resistant to noise, respectively. The $10 \%$ most resistant and the $10 \%$ most sensitive subjects were selected using the HTL at $3 \mathrm{kHz}$ as a measure of noise susceptibility [8].

2.2. Pure Tone Audiometry and Environmental Noise Measurement. As described in a previous study [17], 500, $1000,2000,3000,4000$, and $6000 \mathrm{~Hz}$ pure tone air hearing threshold tests were conducted in a sound-attenuating chamber by an otolaryngologist. The subjects were required to avoid loud noise exposure $(>85 \mathrm{~dB})$ for at least 12 hours prior to the pure tone audiometry. An ascending method in $5 \mathrm{~dB}(\mathrm{~A})$ steps was adopted to ascertain the hearing threshold levels of both ears according to the Diagnostic Criteria of Occupational Noise-Induced Hearing Loss of China [10].

Individual sound pressure noise meters (Noise-Pro, Quest, Oconomowoc, WI USA) were used to measure noise exposure levels for each individual in the workplace at 10 a.m., 3 p.m., and 5 p.m. for three consecutive days.

2.3. SNP Selection. For the aim of the current study, the analysis of the genotyping data was focused on candidate SNPs located in genes involved in the base excision repair pathway. First, SNPs were selected based on the data of the 1000 Genomes Project and dbSNP (https://www.ncbi. nlm.nih.gov/), as well as a primary literature review. The criteria for identifying SNPs included a minor allele frequency (MAF) in the Han Chinese population (CHB) of $>0.10$ and the linkage disequilibrium (LD) $r^{2}>0.8$. Following that, we screened out the SNPs which were located in functional regions of the genes (missense, $3^{\prime} \mathrm{UTR}$, and $5^{\prime}$ UTR) or were previously reported to be involved in human diseases. Finally, rs2072668, rs1130409, and rs1799782 met our requirements and were used for subsequent experiments.

2.4. SNP Genotyping. Genomic DNA was extracted from $200 \mu \mathrm{L}$ of peripheral blood samples using the QIAcube HT and QIAamp 96 DNA QIAcube HT Kits (Qiagen, Dusseldorf, Germany). The three SNPs, rs2072668, rs1130409, and rs1799782, were genotyped using the ABI TaqMan SNP genotyping assay on the ABI 7900HT system (Applied Biosystems, Foster City, CA, USA). The genotyping results were analyzed using the ABI SDS 2.4 Software (Applied Biosystems).

2.5. Statistical Analysis. The chi-square goodness-of-fit test was used to evaluate the deviation of the genotype frequencies of the three SNPs from the Hardy-Weinberg equilibrium (HWE) in the $10 \%$ most sensitive subjects. Comparison of the distribution of the $h O G G 1, A P E X 1$, and XRCC1 genotypes between sensitive and resistant individuals was conducted using Pearson's chi-square test. Multivariate unconditional logistic regression adjusted for age, sex, tobacco use, and alcohol consumption was performed to estimate the odds ratio (OR) and 95\% confidence interval (95\% CI) for the associations of the selected SNPs with NIHL risk. Generalized multifactor dimensionality reduction (GMDR), a generalized combinatorial approach for detecting gene-by-gene and gene-by-environment interactions, adopts dimension reduction strategy to discover interactions [19]. GMDR v0.9 
TABle 1: Demographic characteristics of study subjects.

\begin{tabular}{|c|c|c|c|c|c|}
\hline \multirow[t]{2}{*}{ Variables } & \multicolumn{2}{|c|}{$\begin{array}{l}\text { Sensitive group } \\
\quad(n=117)\end{array}$} & \multicolumn{2}{|c|}{$\begin{array}{l}\text { Resistant group } \\
\quad(n=117)\end{array}$} & \multirow[t]{2}{*}{$P$} \\
\hline & $n$ & $\%$ & $n$ & $\%$ & \\
\hline \multicolumn{6}{|l|}{ Age (years) } \\
\hline Mean \pm SD & \multicolumn{2}{|c|}{$40.72 \pm 6.60$} & \multicolumn{2}{|c|}{$41.87 \pm 4.56$} & $0.121^{\mathrm{a}}$ \\
\hline \multicolumn{6}{|l|}{ Sex } \\
\hline Male & 112 & 95.7 & 109 & 93.2 & \multirow[t]{2}{*}{$0.392^{\mathrm{b}}$} \\
\hline Female & 5 & 4.3 & 8 & 6.8 & \\
\hline \multicolumn{6}{|l|}{ Tobacco use } \\
\hline Now & 59 & 50.4 & 61 & 52.1 & \multirow[t]{3}{*}{$0.249^{\mathrm{b}}$} \\
\hline Ever & 3 & 2.6 & 8 & 6.8 & \\
\hline Never & 55 & 47.0 & 48 & 41.0 & \\
\hline \multicolumn{6}{|c|}{ Alcohol consumption } \\
\hline Now & 40 & 34.2 & 51 & 43.6 & \multirow[t]{3}{*}{$0.374^{\mathrm{c}}$} \\
\hline Ever & 3 & 2.6 & 3 & 2.6 & \\
\hline Never & 74 & 63.2 & 2.6 & 53.8 & \\
\hline \multicolumn{6}{|c|}{ Work time with noise (years) } \\
\hline Mean \pm SD & \multicolumn{2}{|c|}{$19.18 \pm 7.67$} & \multicolumn{2}{|c|}{$18.79 \pm 6.94$} & $0.288^{\mathrm{a}}$ \\
\hline \multicolumn{6}{|c|}{ Expose level with noise (dB) } \\
\hline Mean \pm SD & \multicolumn{2}{|c|}{$87.01 \pm 8.11$} & \multicolumn{2}{|c|}{$87.01 \pm 6.37$} & $1.000^{\mathrm{a}}$ \\
\hline \multicolumn{6}{|c|}{ Hearing threshold level $(\mathrm{dB})$} \\
\hline Mean \pm SD & \multicolumn{2}{|c|}{$52.35 \pm 6.63$} & \multicolumn{2}{|c|}{$8.98 \pm 2.27$} & $<0.001$ \\
\hline$<26$ & 0 & 0 & 117 & 100.0 & \\
\hline$\geq 26$ & 117 & 100 & 0 & 0.0 & \\
\hline
\end{tabular}

${ }^{\mathrm{a}}$ Students' $t$-test; ${ }^{\mathrm{b}}$ Two-sided $\chi^{2}$ test; ${ }^{\mathrm{c}}$ Fisher's exact test.

software was used to explore the interactions of the three selected SNPs with environmental factors. All statistical analyses were performed using the SPSS 24.0 software (IBM, NYC, USA), and values of $P<0.05$ were considered statistically significant.

\section{Results}

3.1. Demographic Characteristics of the Study Subjects and the Hardy-Weinberg Test. General demographic and lifestyle features (age, sex, tobacco, and alcohol consumption habits), duration of noise-exposed work time, noise intensity, and high-frequency hearing threshold of the sensitive and resistant groups are shown in Table 1. There was no significant difference between sensitive and resistant subjects regarding general characteristics and lifestyle features, duration of noise-exposed work time, and noise intensity $(P>0.05)$. However, the average high-frequency hearing threshold was significantly higher in the sensitive group $(52.35 \pm 6.63 \mathrm{~dB})$ than the resistant group $(8.98 \pm 2.27 \mathrm{~dB})(P<0.001)$. General data of the selected SNPs and the Hardy-Weinberg test results are shown in Table 2. Rs2072668 of hOGG1, rs1799782 of XRCC1, and rs1130409 of APEX1 are intron, missense, and missense variants, respectively. All selected SNPs have minor allele frequencies $\geq 5 \%$ and are within the Hardy-Weinberg equilibrium (HWE) $(P>0.05)$.
3.2. Single SNP Analysis. Table 3 shows genotype frequencies of the sensitive and resistant groups. The $P$ values resulting after statistical analysis of the single SNPs were also presented. In the codominant model, rs1799782 TT, rs1130409 GG, and rs1130409 GT were shown to be more frequent in the sensitive group $(P=0.005, \mathrm{OR}=8.92,95 \% \mathrm{CI}=1.91$ to 41.63; $P=0.039, \mathrm{OR}=2.21,95 \% \mathrm{CI}=1.04$ to $4.70 ; P=0.004$, $\mathrm{OR}=2.48,95 \% \mathrm{CI}=1.34$ to 4.61 , respectively). For the rs1130409 dominant model, genotypes GG and GT were found to be more frequent in the sensitive group (76.1\%) compared to the resistant group $(58.1 \%)(P=0.003, \mathrm{OR}=2.39$, $95 \% \mathrm{CI}=1.34$ to 4.27$)$. Genotype TT was more frequent in the sensitive group (12.0\%) compared to the resistant group $(1.7 \%)$ in the rs 1799782 recessive model with an OR of 8.83 $(P=0.005,95 \% \mathrm{CI}=1.93$ to 40.36$)$. Furthermore, compared to the rs1799782 $\mathrm{C}$ allele frequency, the $\mathrm{T}$ allele frequency was shown to be increased in the sensitive group $(P=0.046$, $\mathrm{OR}=1.51,95 \% \mathrm{CI}=1.01$ to 2.26$)$. In addition, the $\mathrm{rs} 1130409$ $G$ allele frequency was also increased in the sensitive group compared to the resistant group $(P=0.015, \mathrm{OR}=1.59,95 \%$ $\mathrm{CI}=1.10$ to 2.31 ).

3.3. Stratification Analysis. Stratified analyses of SNPs were conducted under the allelic model, and the results were presented in Table 4. An increased risk was evident in individuals with more than $95 \mathrm{~dB}(\mathrm{~A})$ cumulative noise 
TABLE 2: General information of selected SNPs and the Hardy-Weinberg test.

\begin{tabular}{lccccccc}
\hline \multirow{2}{*}{ Gene } & \multirow{2}{*}{ SNP } & \multirow{2}{*}{ Alleles } & \multirow{2}{*}{ Chromosome } & Functional consequence & \multicolumn{2}{c}{ Control $^{\mathrm{a}}$} & Database $^{*} P$ for HWE $^{\mathrm{b}}$ \\
\hline hOGG1 & $\mathrm{rs} 2072668$ & $\mathrm{C} / \mathrm{G}$ & $3: 9756456$ & Intron variant & 0.376 & 0.378 \\
XRCC1 & rs1799782 & C/T & $19: 43553422$ & Missense & 0.296 & 0.267 & 0.926 \\
APEX1 & rs1130409 & G/T & $14: 20456995$ & Missense & 0.438 & 0.452 & 0.529 \\
\hline
\end{tabular}

${ }^{\mathrm{a}}$ Data from NCBI dbSNP; ${ }^{\mathrm{b}} \mathrm{P}$ value of the Hardy-Weinberg test.

TABLE 3: Distribution of three polymorphisms and the association with NIHL.

\begin{tabular}{|c|c|c|c|c|c|c|c|}
\hline \multirow{2}{*}{ Genetic models } & \multirow{2}{*}{ Genotypes } & \multicolumn{2}{|c|}{ Sensitive group } & \multicolumn{2}{|c|}{ Resistant group } & \multirow{2}{*}{ Adjusted $P^{\mathrm{a}}$} & \multirow{2}{*}{ Adjusted OR $(95 \% \mathrm{CI})^{\mathrm{a}}$} \\
\hline & & $n=117$ & $\%$ & $n=117$ & $\%$ & & \\
\hline \multicolumn{8}{|l|}{ rs2072668 } \\
\hline \multirow{3}{*}{ Codominant } & GG & 34 & 29.1 & 39 & 33.3 & & 1.00 (ref.) \\
\hline & CC & 15 & 14.5 & 17 & 14.5 & 0.874 & $1.07(0.45-2.55)$ \\
\hline & CG & 68 & 52.1 & 61 & 52.1 & 0.359 & $1.32(0.73-2.38)$ \\
\hline \multirow{2}{*}{ Dominant } & GG & 34 & 29.1 & 39 & 33.3 & & 1.00 (ref.) \\
\hline & $\mathrm{CC}+\mathrm{CG}$ & 83 & 70.9 & 78 & 66.7 & 0.414 & $1.27(0.72-2.25)$ \\
\hline \multirow{2}{*}{ Recessive } & $\mathrm{CG}+\mathrm{GG}$ & 102 & 87.2 & 100 & 85.5 & & 1.00 (ref.) \\
\hline & $\mathrm{CC}$ & 15 & 12.8 & 17 & 14.5 & 0.766 & $0.89(0.41-1.92)$ \\
\hline \multirow{2}{*}{ Alleles } & G & 136 & 58.1 & 139 & 59.4 & & 1.00 (ref.) \\
\hline & $\mathrm{C}$ & 98 & 41.9 & 95 & 40.6 & 0.695 & $1.08(0.74-1.57)$ \\
\hline \multicolumn{8}{|l|}{ rs1799782 } \\
\hline \multirow{3}{*}{ Codominant } & $\mathrm{CC}$ & 51 & 43.6 & 59 & 50.4 & & 1.00 (ref.) \\
\hline & $\mathrm{CT}$ & 52 & 44.4 & 56 & 47.9 & 0.940 & $1.02(0.59-1.76)$ \\
\hline & $\mathrm{TT}$ & 14 & 12.0 & 2 & 1.7 & 0.005 & $8.92(1.91-41.63)$ \\
\hline \multirow{2}{*}{ Dominant } & $\mathrm{CC}$ & 51 & 43.6 & 59 & 50.4 & & 1.00 (ref.) \\
\hline & $\mathrm{CT}+\mathrm{TT}$ & 66 & 56.4 & 58 & 49.6 & 0.344 & $1.29(0.76-2.17)$ \\
\hline \multirow{2}{*}{ Recessive } & $\mathrm{CC}+\mathrm{CT}$ & 103 & 88.0 & 115 & 98.3 & & 1.00 (ref.) \\
\hline & TT & 14 & 12.0 & 2 & 1.7 & 0.005 & $8.83(1.93-40.36)$ \\
\hline \multirow{2}{*}{ Alleles } & $\mathrm{C}$ & 154 & 65.8 & 174 & 74.4 & & 1.00 (ref.) \\
\hline & $\mathrm{T}$ & 80 & 34.2 & 60 & 25.6 & 0.046 & $1.51(1.01-2.26)$ \\
\hline \multicolumn{8}{|l|}{ rs1130409 } \\
\hline \multirow{3}{*}{ Codominant } & TT & 28 & 23.9 & 49 & 41.9 & & 1.00 (ref.) \\
\hline & GG & 26 & 22.2 & 21 & 17.9 & 0.039 & $2.21(1.04-4.70)$ \\
\hline & GT & 63 & 53.8 & 47 & 40.2 & 0.004 & $2.48(1.34-4.61)$ \\
\hline \multirow{2}{*}{ Dominant } & $\mathrm{TT}$ & 28 & 23.9 & 49 & 41.9 & & 1.00 (ref.) \\
\hline & $\mathrm{GG}+\mathrm{GT}$ & 89 & 76.1 & 68 & 58.1 & 0.003 & $2.39(1.34-4.27)$ \\
\hline \multirow{2}{*}{ Recessive } & GG & 26 & 22.2 & 21 & 17.9 & & 1.00 (ref.) \\
\hline & $\mathrm{GT}+\mathrm{TT}$ & 91 & 77.8 & 96 & 82.1 & 0.428 & $1.30(0.68-2.51)$ \\
\hline \multirow{2}{*}{ Alleles } & $\mathrm{T}$ & 119 & 50.9 & 145 & 62.0 & & 1.00 (ref.) \\
\hline & G & 115 & 49.1 & 89 & 38.0 & 0.015 & $1.59(1.10-2.31)$ \\
\hline
\end{tabular}

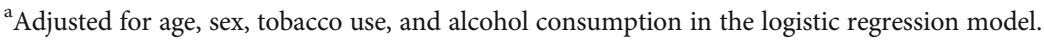

exposure who carried the XRCC1 rs1799782 $\mathrm{T}$ allele (adjusted $\mathrm{OR}=1.76,95 \% \mathrm{CI}=1.05$ to 2.98 ).

3.4. Gene and Environment Interaction Analysis. We used the GMDR v0.9 software to detect the interaction of the three selected SNPs with environmental factors. Table 5 shows the best fit model, testing balanced accuracy, cross-validation
(CV) consistency, and $P$ values obtained. In all models, rs1130409, rs1130409-drinking, and rs1799782-rs1130409smoking were the best fit models. The analysis showed that rs1130409 and drinking had a statistically significant interaction $(P=0.0002, \mathrm{OR}=2.77,95 \% \mathrm{CI}=1.61$ to 4.77$)$. Rs1799782, rs1130409, and smoking also had a statistically significant interaction with $P<0.0001$ (OR $=3.71$, 
TABLE 4: Stratified analysis of SNPs in the allelic model.

\begin{tabular}{|c|c|c|c|c|}
\hline \multirow{2}{*}{ SNPs } & \multirow{2}{*}{ Group } & \multirow{2}{*}{ Alleles } & \multicolumn{2}{|c|}{ Cumulative noise exposure $(\mathrm{dB})$} \\
\hline & & & $\leq 95$ & $>95$ \\
\hline \multirow{6}{*}{ rs2072668 } & \multirow{2}{*}{ Sensitive group } & $\mathrm{C}$ & 17 & 81 \\
\hline & & G & 29 & 107 \\
\hline & \multirow{2}{*}{ Resistant group } & $\mathrm{C}$ & 46 & 49 \\
\hline & & G & 64 & 75 \\
\hline & Adjusted $P^{\mathrm{a}}$ & & 0.613 & 0.390 \\
\hline & Adjusted OR $(95 \% \mathrm{CI})^{\mathrm{a}}$ & & $0.83(0.39-1.73)$ & $1.23(0.76-1.99)$ \\
\hline \multirow{6}{*}{ rs1799782 } & \multirow{2}{*}{ Sensitive group } & $\mathrm{C}$ & 31 & 123 \\
\hline & & $\mathrm{T}$ & 15 & 65 \\
\hline & \multirow{2}{*}{ Resistant group } & $\mathrm{C}$ & 79 & 95 \\
\hline & & $\mathrm{T}$ & 31 & 29 \\
\hline & $P^{\mathrm{a}}$ & & 0.611 & 0.034 \\
\hline & Adjusted OR $(95 \% \mathrm{CI})^{\mathrm{a}}$ & & $1.22(0.57-2.63)$ & $1.76(1.05-2.98)$ \\
\hline \multirow{6}{*}{ rs1130409 } & \multirow{2}{*}{ Sensitive group } & G & 20 & 95 \\
\hline & & $\mathrm{T}$ & 26 & 93 \\
\hline & \multirow{2}{*}{ Resistant group } & G & 38 & 51 \\
\hline & & $\mathrm{T}$ & 72 & 73 \\
\hline & $P^{\mathrm{a}}$ & & 0.309 & 0.126 \\
\hline & Adjusted OR $(95 \% \mathrm{CI})^{\mathrm{a}}$ & & $1.46(0.71-3.03)$ & $1.44(0.90-2.30)$ \\
\hline
\end{tabular}

dB: decibel; ${ }^{a}$ Adjusted for age, sex, tobacco use, and alcohol consumption in the logistic regression model.

TABLE 5: Analysis of the interaction by GMDR.

\begin{tabular}{|c|c|c|c|c|c|}
\hline Best model & Training balanced accuracy & Testing balanced accuracy & $\begin{array}{l}\text { Cross-validation } \\
\text { consistency }\end{array}$ & $P$ & OR (95\% CI) \\
\hline rs1130409 & 0.5897 & 0.5897 & $10 / 10$ & 0.0037 & $2.29(1.31-4.02)$ \\
\hline rs1130409*drink & 0.6211 & 0.5641 & $7 / 10$ & 0.0002 & $2.77(1.61-4.77)$ \\
\hline rs1799782* rs1130409* smoke & 0.6629 & 0.5513 & $5 / 10$ & $<0.0001$ & $3.71(2.16-6.38)$ \\
\hline
\end{tabular}

$95 \% \mathrm{CI}=2.16$ to 6.38 ). Diagrams of the best fit model are shown in Figure 1.

\section{Discussion}

Our results showed a statistically significant association of the rs1799782 TT genotype located in the XRCC1 coding region and the rs $1130409 \mathrm{GG} / \mathrm{GT}$ in the APEX1 encoding region with an increased risk of NIHL in a Chinese population. Notably, the APEX1 rs1130409 polymorphism has been previously reported to contribute to the susceptibility of NIHL in an Eastern Chinese population by Shen et al. Thereby, our results provide additional evidence that APEX1 rs1130409 is a potential gene involved in NIHL susceptibility. Moreover, rs1799782 XRCC1 was shown to be associated with NIHL susceptibility in a Chinese population for the first time.

$X R C C 1$ is a $33 \mathrm{~kb}$ long gene located in the chromosome $19 q 13.3$ region. It consists of 17 exons and encodes a $2.2 \mathrm{~kb}$ transcript, producing the X-ray cross-complementing group 1 protein. It has potential interactions with DNA polymerase- $\beta$ (POLB), poly ADP ribose polymerase (PARP), and DNA ligase III in the BER pathway. The rs1799782 (Arg194Trp, 580C > T) mutation within the XRCC1 gene leads to a change in amino acids. These changes may alter the efficiency of XRCC1 in DNA repair and may have vital functional significance. Previously published research showed that the XRCC1 gene codon 194 (rs1799782) is located at a conserved residue in the human genome, indicating that this polymorphism may have functional significance [20]. Moreover, there are studies that suggest that protein function can be affected by amino acid substitutions in evolutionarily conserved regions [21]. However, the functional effect of XRCC1 rs1799782 is not yet well understood.

Another enzyme that plays a primary role in base excision repair is APEX1. APEX1 completes the restoration of DNA damage by excising abasic residues and poly polymerase- 1 binding in DNA containing strand breaks, DNA polymerase- $\beta$, polynucleotide kinase, and DNA ligase III. For the rs1130409 (Asp148Glu, -656T>G) polymorphism of $A P E X 1$, functional studies suggest that mutation to a $\mathrm{G}$ allele may alter endonuclease DNA-binding activity, reduce 


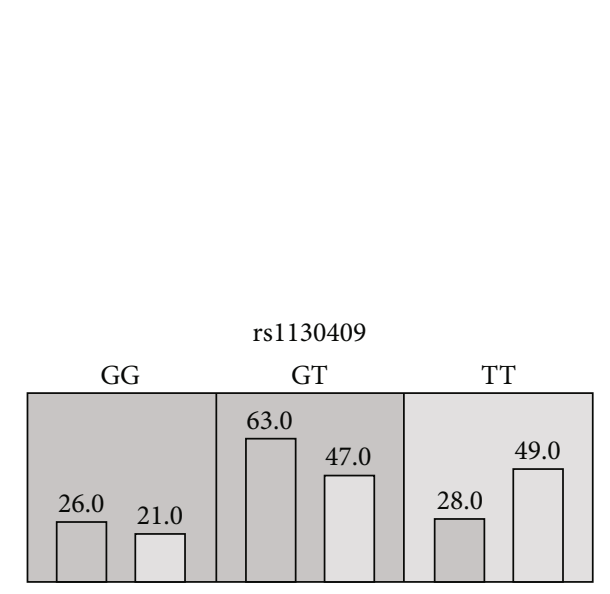

(a)

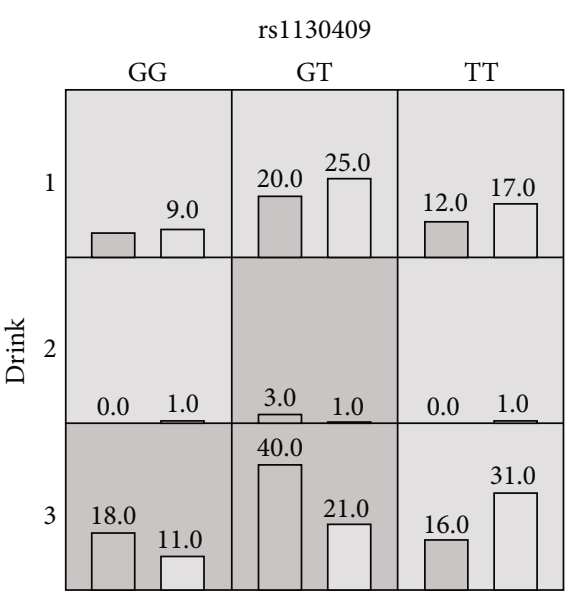

(b)

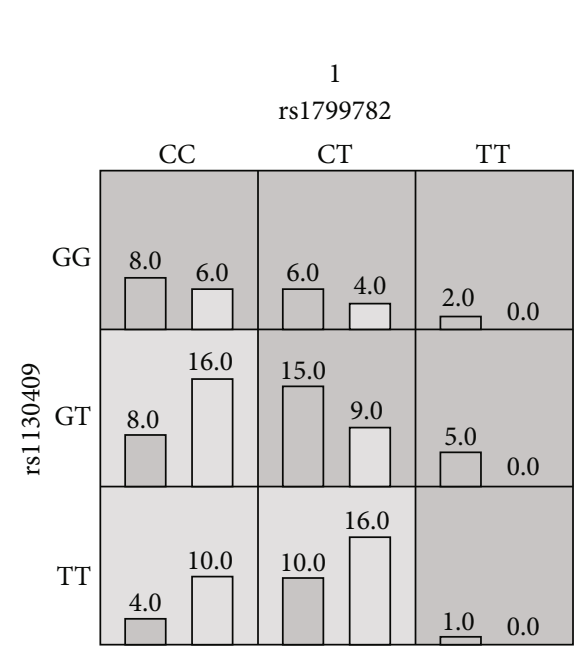

Smoke

2

rs1799782

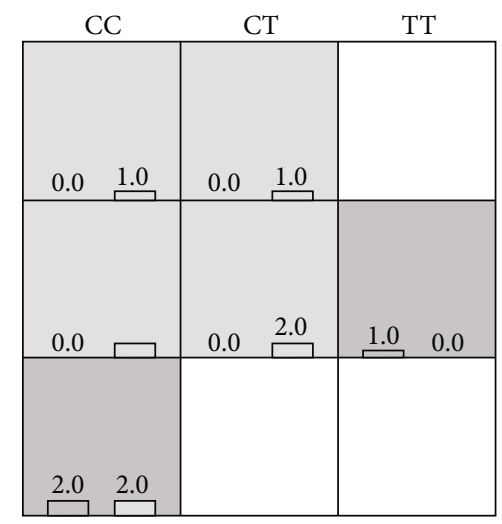

(c)

FIGURE 1: The best fit model gained by the analysis of GMDR. The implications of bars and background color in each multifactor cell are as follows. The left bars represent the sum of scores in the case and the right represents the control. High-risk cells are expressed by black shadow if the ratio of the number of cases to the number of controls exceeds the preset value $T$, as low-risk cells by light shadow if not more than the threshold and empty cells by no shadow which means no cases and controls. The multifactor cells labeled as "high risk" or "low risk" are then used to assess the classification and prediction accuracy, thus identifying the best model in the subsequent steps (drink 1: now, 2: ever, 3: never; smoke 1: now, 2: ever, 3: never).

its ability to communicate with other base excision repair proteins, and decrease its capacity to repair DNA damage induced by oxidative stress $[22,23]$.

Several studies have reported on the adverse effects of smoking on hearing ability [24, 25]. Likewise, our results showed an interaction between cigarette use and SNPs (rs1799782 and rs1130409) with an NIHL risk of OR $=3.71$. Adverse effects were also observed between alcohol consumption and NIHL in this study. However, there are still controversies regarding the effects of smoking and drinking on hearing loss. As such, further studies are required to confirm these findings $[26,27]$.

Our study was the first to investigate the association between the XRCC1 rs1799782 and APEX1 rs1130409 polymorphisms and NIHL risk. One limitation of our study was that the workers enrolled in our study were exposed to steady noise for more than 20 years but have lower levels of exposure to other occupational hazards. Moreover, the NIHL workers with both a low- and high-frequency hearing range worse than $25 \mathrm{~dB}$ were all transferred from noisy environments. Therefore, a selection bias may exist in our study.

\section{Conclusion}

Our findings support a potential association of the XRCC1 rs1799782 and APEX1 rs1130409 variants with inherited susceptibility to NIHL. However, the concrete mechanism underlying NIHL association with XRCC1 rs1799782 and APEX1 rs1130409 will need to be investigated in future studies.

\section{Data Availability}

The data used to support the findings of this study are available from the corresponding authors upon request. General characteristics of the patients are presented in Table 1. 


\section{Conflicts of Interest}

No potential conflict of interest relevant to this article was reported.

\section{Authors' Contributions}

Enmin Ding performed the experiments and wrote the paper. Jiadi Guo collected the specimens. Xin Ge, Rongjian Sheng, and Jian Chen statistically analyzed the data. Hengdong Zhang and Baoli Zhu designed the research and wrote the paper. All authors read and approved the final manuscript. Enmin Ding, Jiadi Guo, and Xin Ge contributed equally to the research.

\section{Acknowledgments}

We would like to thank the workers for their contribution to our research. Research reported in this publication was supported by Jiangsu Province's Outstanding Medical Academic Leader program (CXTDA2017029) and Natural Science Foundation of Jiangsu Province (BK20181488).

\section{References}

[1] L. Van Laer, P. I. Carlsson, N. Ottschytsch et al., "The contribution of genes involved in potassium-recycling in the inner ear to noise-induced hearing loss," Human Mutation, vol. 27, no. 8, pp. 786-795, 2006.

[2] M. Sliwinska-Kowalska and M. Pawelczyk, "Contribution of genetic factors to noise-induced hearing loss: a human studies review," Mutation Research/Reviews in Mutation Research, vol. 752, no. 1, pp. 61-65, 2013.

[3] D. B. Kirchner, E. Evenson, R. A. Dobie et al., "Occupational noise-induced hearing loss: ACOEM Task Force on Occupational Hearing Loss," Journal of Occupational and Environmental Medicine, vol. 54, no. 1, pp. 106-108, 2012.

[4] A. Lie, M. Skogstad, H. A. Johannessen et al., "Occupational noise exposure and hearing: a systematic review," International Archives of Occupational and Environmental Health, vol. 89, no. 3, pp. 351-372, 2016.

[5] H. Guo, E. Ding, Y. Bai et al., "Association of genetic variations in FOXO3 gene with susceptibility to noise induced hearing loss in a Chinese population," PLoS One, vol. 12, no. 12, article e0189186, 2017.

[6] E. Ding, J. Liu, H. Guo et al., "DNMT1 and DNMT3A haplotypes associated with noise-induced hearing loss in Chinese workers," Scientific Reports, vol. 8, no. 1, article 12193, p. 12193, 2018.

[7] A. Konings, L. Van Laer, S. Michel et al., "Variations in HSP70 genes associated with noise-induced hearing loss in two independent populations," European Journal of Human Genetics, vol. 17, no. 3, pp. 329-335, 2009.

[8] A. Konings, L. Van Laer, M. Pawelczyk et al., "Association between variations in CAT and noise-induced hearing loss in two independent noise-exposed populations," Human Molecular Genetics, vol. 16, no. 15, pp. 1872-1883, 2007.

[9] M. Pawelczyk, L. Van Laer, E. Fransen et al., "Analysis of gene polymorphisms associated with $\mathrm{K}^{+}$ion circulation in the inner ear of patients susceptible and resistant to noise-induced hearing loss," Annals of Human Genetics, vol. 73, no. 4, pp. 411-421, 2009.

[10] E. Ding, J. Liu, H. Shen et al., "Notch polymorphisms associated with sensitivity of noise induced hearing loss among Chinese textile factory workers," BMC Medical Genetics, vol. 19, no. 1, p. 168, 2018.

[11] E. C. Friedberg, L. D. McDaniel, and R. A. Schultz, "The role of endogenous and exogenous DNA damage and mutagenesis," Current Opinion in Genetics \& Development, vol. 14, no. 1, pp. 5-10, 2004.

[12] C. E. Caldon, "Estrogen signaling and the DNA damage response in hormone dependent breast cancers," Frontiers in Oncology, vol. 4, p. 106, 2014.

[13] S. P. Jackson and J. Bartek, "The DNA-damage response in human biology and disease," Nature, vol. 461, no. 7267, pp. 1071-1078, 2009.

[14] P. A. Muniandy, J. Liu, A. Majumdar, S. T. Liu, and M. M. Seidman, "DNA interstrand crosslink repair in mammalian cells: step by step," Critical Reviews in Biochemistry and Molecular Biology, vol. 45, no. 1, pp. 23-49, 2010.

[15] S. Madhusudan, F. Smart, P. Shrimpton et al., "Isolation of a small molecule inhibitor of DNA base excision repair," Nucleic Acids Research, vol. 33, no. 15, pp. 4711-4724, 2005.

[16] S. M. Farrington, A. Tenesa, R. Barnetson et al., "Germline susceptibility to colorectal cancer due to base-excision repair gene defects," The American Journal of Human Genetics, vol. 77, no. 1, pp. 112-119, 2005.

[17] H. Shen, J. Cao, Z. Hong et al., “A functional Ser326Cys polymorphism in $h O G G 1$ is associated with noise-induced hearing loss in a Chinese population," PLoS One, vol. 9, no. 3, article e89662, 2014.

[18] H. Shen, J. Dou, L. Han et al., "Genetic variation in APE1 gene promoter is associated with noise-induced hearing loss in a Chinese population," International Archives of Occupational and Environmental Health, vol. 89, no. 4, pp. 621-628, 2016.

[19] X. Y. Lou, G. B. Chen, L. Yan et al., “A generalized combinatorial approach for detecting gene-by-gene and gene-byenvironment interactions with application to nicotine dependence," The American Journal of Human Genetics, vol. 80, no. 6, pp. 1125-1137, 2007.

[20] J. E. Lamerdin, M. A. Montgomery, S. A. Stilwagen et al., "Genomic sequence comparison of the human and mouse XRCC1 DNA repair gene regions," Genomics, vol. 25, no. 2, pp. 547-554, 1995.

[21] S. Savas, D. Y. Kim, M. F. Ahmad, M. Shariff, and H. Ozcelik, "Identifying functional genetic variants in DNA repair pathway using protein conservation analysis," Cancer Epidemiology, Biomarkers \& Prevention, vol. 13, no. 5, pp. 801-807, 2004.

[22] M. Z. Hadi, M. A. Coleman, K. Fidelis, H. W. Mohrenweiser, and Wilson DM 3rd, "Functional characterization of Ape1 variants identified in the human population," Nucleic Acids Research, vol. 28, no. 20, pp. 3871-3879, 2000

[23] W. W. Au, S. A. Salama, and C. H. Sierra-Torres, "Functional characterization of polymorphisms in DNA repair genes using cytogenetic challenge assays," Environmental Health Perspectives, vol. 111, no. 15, pp. 1843-1850, 2003.

[24] T. Mizoue, T. Miyamoto, and T. Shimizu, "Combined effect of smoking and occupational exposure to noise on hearing loss in steel factory workers," Occupational and Environmental Medicine, vol. 60, no. 1, pp. 56-59, 2003. 
[25] K. T. Palmer, M. J. Griffin, H. E. Syddall, and D. Coggon, "Cigarette smoking, occupational exposure to noise, and self reported hearing difficulties," Occupational and Environmental Medicine, vol. 61, no. 4, pp. 340-344, 2004.

[26] M. Nakamura, N. Aoki, T. Nakashima et al., "Smoking, alcohol, sleep and risk of idiopathic sudden deafness: a casecontrol study using pooled controls," Journal of Epidemiology, vol. 11, no. 2, pp. 81-86, 2001.

[27] M. M. Popelka, K. J. Cruickshanks, T. L. Wiley et al., "Moderate alcohol consumption and hearing loss: a protective effect," Journal of the American Geriatrics Society, vol. 48, no. 10, pp. 1273-1278, 2000. 


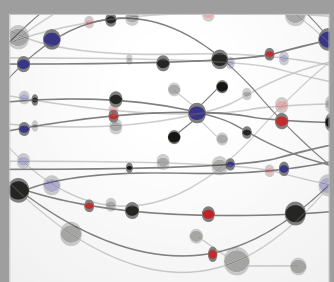

The Scientific World Journal
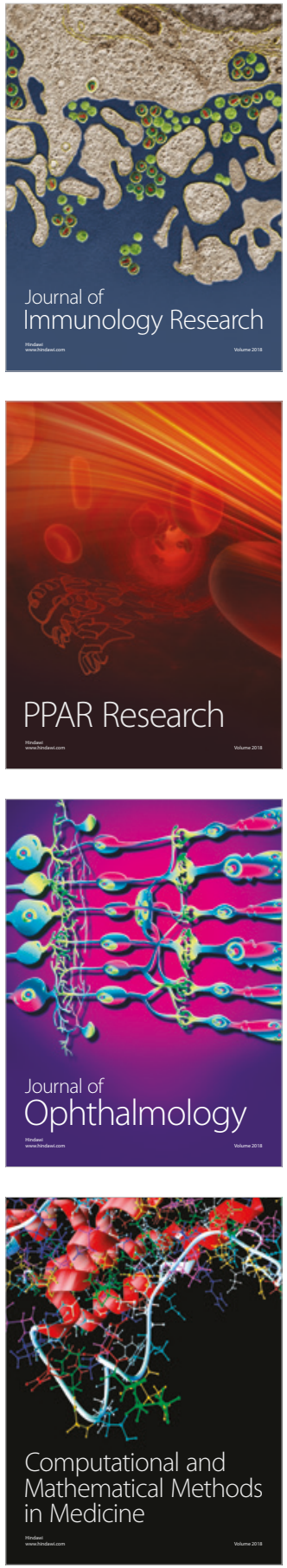

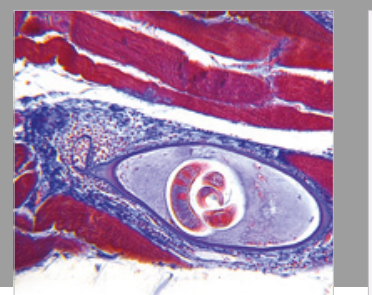

Gastroenterology Research and Practice

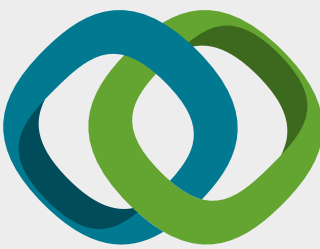

\section{Hindawi}

Submit your manuscripts at

www.hindawi.com
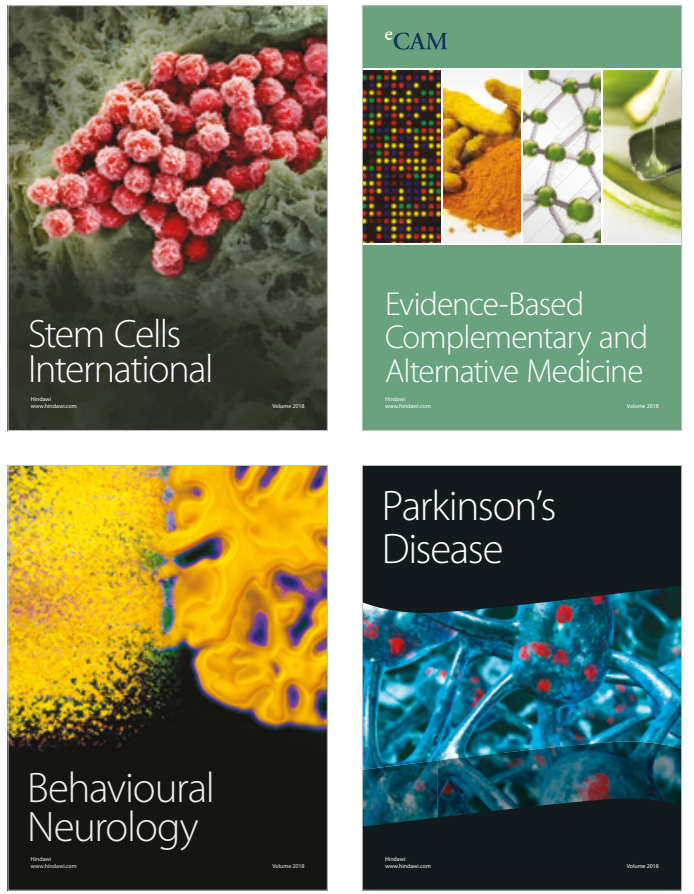

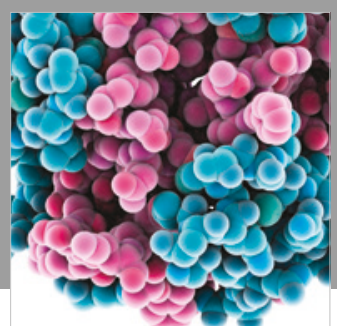

ournal of

Diabetes Research

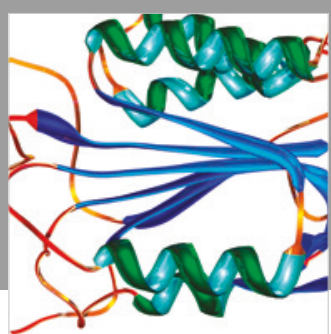

Disease Markers
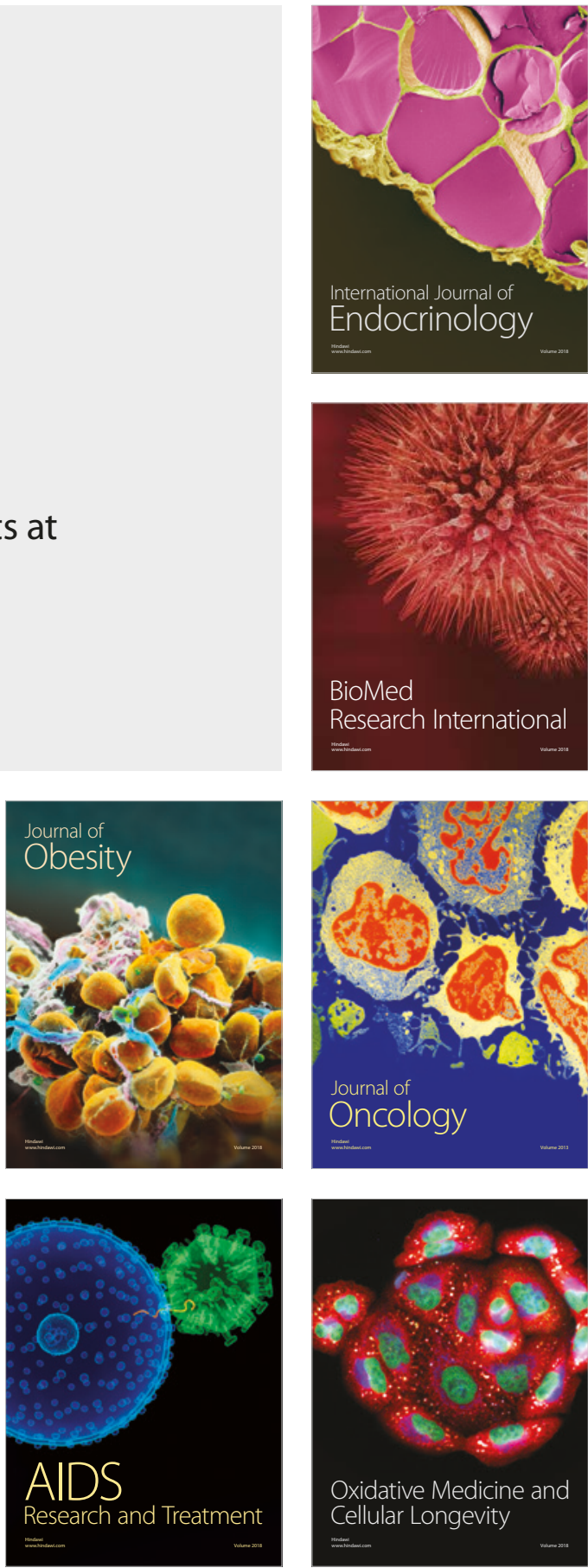